\title{
* Ampliación de derechos por el defensor del pueblo: relectura iusfundamental
}

\author{
Extension of rights by the \\ ombudsman: iusfundamental \\ rereading
}

\author{
GUILLERMO ESCOBAR ROCA \\ Catedrático de Derecho Constitucional. \\ Universidad de Alcalá. \\ guillermo.escobar@uah.es
}

DOI: https://doi.org/10.7203/cc.2.22173

Fecha de recepción: 16/09/2021

Fecha de aceptación: 04/10/2021

\section{Resumen}

El catálogo y el contenido de los derechos fundamentales son abiertos, y el Defensor del Pueblo contribuye "desde abajo" a la tarea colectiva de justificar sus ampliaciones. Sin embargo, su argumentación en derechos contiene serios déficits, que deberían ser corregidos. Así se demuestra en los seis casos analizados, ofreciéndose una construcción alternativa, más coherente con la función constitucionalmente atribuida al Defensor del Pueblo.

Palabras clave

Derechos fundamentales; Defensor del Pueblo; quejas; análisis jurídico; casos.

\section{Abstract}

The catalog and the content of fundamental rights are open, and the Ombudsman contributes "from below" to the collective task of justifying its extensions. However, his argumentation on rights contains serious deficits, which should be corrected. This is demostrated in the six cases analyzed, offering an alternative construction, more consistent with the function constitutionally attributed to the Ombudsman.

\section{Keywords}

Fundamental rights; Ombudsman; complaints; legal analysis; cases. 
I. Planteamiento. - II. La documentación de las personas transexuales, ¿un derecho innominado? - III. Violencia de género: defecto de protección del derecho a la integridad. - IV. ¿Existe un derecho a la ciudad? - V. ¿Derecho fundamental a la reparación de las víctimas del terrorismo? - VI. Nuevas dimensiones de la religión e intimidad: banderas a media asta y divulgación de la homosexualidad. Bibliografía.

\section{Planteamiento}

Los derechos crecen, y a veces (raramente), disminuyen, como en la famosa metáfora del "árbol vivo", léase "interpretación evolutiva", hecha suya por nuestro Tribunal Constitucional'. La ampliación del catálogo de los derechos o creación de "nuevos" derechos (formalmente, ampliación del contenido de los "viejos" derechos ${ }^{2}$ ) suele realizarse por vía jurisprudencial (la reforma constitucional en España ni está ni se la espera), pero al menos los tribunales deberían tomar nota de las aspiraciones sociales, pues si los derechos son para las personas, se supone que estas tendrán algo que decir al respecto.

El Parlamento no siempre es suficientemente representativo (recuérdese uno de los lemas del 15-M) y no todas las demandas ciudadanas llegan a los tribunales; al menos se inadmitirán a trámite las que promuevan reformas constitucionales y legales. Tampoco es razonable convertir en derecho cualquier reivindicación social. El Defensor del Pueblo (en adelante, DP) puede jugar (y de hecho juega, quizás sin saberlo) un papel clave para corregir algunos déficits de la representación (dando voz a los que no la tienen, o al menos a quien no se escucha) y del sistema judicial, ejerciendo además un papel de filtro de demandas ciudadanas poco razonables ${ }^{3}$, en una especie de corrección del populismo.

En este trabajo analizaré algunos casos resueltos por el DP sobre derechos de defensa, bloque este de derechos que, aunque ocupa un lugar quizás

1 STC 198/2012, FJ 9.

2 En nuestro sistema, el catálogo de los derechos es formalmente cerrado, pues no contamos con una cláusula de apertura, tipo Enmienda IX de la Constitución de los Estados Unidos ("No por el hecho de que la Constitución enumera ciertos derechos ha de entenderse que niega o menosprecia otros que retiene el pueblo"), reiterada, por cierto con mejor redacción, en el art. 29 de nuestra Constitución de 1869. Sin embargo, la diferencia entre catálogos abiertos y cerrados en la práctica se diluye; al respecto, Escobar (2018: 32 y ss).

3 Según el art. 17.1 de la Ley Orgánica 3/1981 (en adelante, LODP), el DP puede tramitar o rechazar (en este caso motivadamente) las quejas que se le presenten, pero no dice cuándo puede hacer esto último, por lo que cabe aquí amplia discrecionalidad. 
estadísticamente poco significativo en el conjunto de sus actuaciones ${ }^{4}$, ofrece pistas importantes para verificar el nivel de cumplimiento de una parte importante de nuestro catálogo de derechos fundamentales ${ }^{5}$. El enfoque en los incumplimientos, vulneraciones o violaciones de derechos fundamentales ha sido siempre escaso, pues los académicos especializados en este campo, víctimas muchas veces del llamado positivismo jurisprudencial, suelen centrarse en el estudio de las sentencias (que en su mayoría responden a demandas individuales), descuidando así la perspectiva sistémica, seguramente porque esta se encontraría a caballo entre la sociología del Derecho y la dogmática constitucional (Escobar, 2019: 144-149) ${ }^{6}$, y es que, salvo raras excepciones, ni los sociólogos saben Derecho ni los constitucionalistas saben sociología. Sin embargo, el estudio de las vulneraciones sistémicas o estructurales (más adelante realizaré algunas consideraciones sobre este concepto) debería ser ineludible, al menos si queremos contribuir a mejorar la eficacia de nuestro sistema, pues de poco sirve solucionar problemas individuales si estos se reiteran permanentemente y no se atajan los problemas de fondo.

Para verificar la existencia de vulneraciones estructurales de derechos fundamentales, nada mejor que acudir a las recomendaciones e informes del Defensor. Frente al proceso judicial, el procedimiento ante el DP es más amplio en cuanto a los problemas que aborda, más rápido, económico, accesible, especializado y mejor diseñado para responder a las vulneraciones estructurales, y por todo ello nos ofrece una imagen bastante completa sobre estas. En este trabajo intentaré describir (lo que dice, lo que no dice, y sobre todo cómo lo dice) la doctrina del DP sobre algunos derechos de defensa, en respuesta a problemas que cabría calificar como sistémicos o que conllevan recomendaciones generales ${ }^{7}$, con especial atención a las recomendaciones de reforma

4 El DP no sistematiza sus informes anuales por derechos sino por áreas de actuación administrativa (18 en concreto, a las que añade su trabajo como Mecanismo Nacional de Prevención de la Tortura), y de hecho muchas veces resulta difícil encontrar en su doctrina un razonamiento en clave de derechos, lo que no parece muy coherente con su función constitucional de "defensa de los derechos" (art. 54 CE). En cuanto a sus "resoluciones" (que es el nombre que la web de la institución otorga al conjunto de recomendaciones -en sentido estricto-, sugerencias, recordatorios de deberes legales y advertencias, que son las denominaciones que utiliza el art. 30.1 LODP), tampoco se encuentran sistematizadas por derechos, aunque sí algunas, significativamente, por "grupos sociales" (cuyos derechos han sido vulnerados, se entiende). No costaría mucho, al menos, "etiquetar" cada recomendación por el derecho afectado en cada caso, pues incluso las que no encajan claramente en ninguno podrían ser encuadradas bajo el epígrafe genérico del derecho a la buena administración. En al menos 22 países europeos los informes anuales se estructuran por derechos (el listado en Kucsko, 2008: 504). Como ejemplo de la posibilidad de esta "traducción" de problemas denunciados a intervenciones sobre derechos, puede verse Escobar (2017).

5 Según la Constitución y la ley, el DP protege los derechos fundamentales (de la Constitución), no los derechos humanos (de los tratados internacionales). Sería deseable que en el futuro la ley incluyera expresamente (aunque en la práctica creo que se podrían proteger también) a estos últimos, como sucede en casi toda Latinoamérica: los datos, dentro del apartado "parámetro de control", en cada uno de los capítulos de Escobar (2008). En Europa, al menos en doce países la legislación del Ombudsman incluye expresamente el Derecho internacional de los derechos humanos como parámetro de control (Kucsko, 2008: 38).

6 Últimamente, Arlettaz y Gracia (2020: 247-250), destacando correctamente las interacciones. Más en general, Fariñas (1994: 1019-1023).

7 A diferencia, entre otros, del caso mexicano, este término (que emparentaría con la figura de los "fallos estructurales") no figura expresamente en nuestra legislación. La identificación de estas recomendaciones resulta relativamente sencilla si atendemos a su "fallo": serían generales o estructurales aquellas que recomiendan la modificación o creación de una norma jurídica o de lo que podríamos denominar una política pública general, esto es, no limitada a un caso concreto, aunque el procedimiento haya partido de él. 
o de creación de normas; como se verá, se trata de respuestas originales a problemas apenas planteados en los tribunales y que por tanto arrojan nuevas perspectivas sobre nuestro modelo de derechos fundamentales. Si bien el DP ha sido objeto de numerosas investigaciones ${ }^{8}$, se pueden contar con los dedos de una mano las centradas en el análisis de su doctrina, que sin duda es lo más interesante ${ }^{9}$. Esta modesta contribución pretende tan solo iniciar un camino apenas transitado entre nosotros ${ }^{10}$.

\section{La documentación de las personas transexuales, ¿un derecho innominado?}

El cambio de sexo no se encuentra expresamente reconocido por ley nacional'1, aunque sí de forma indirecta, en la medida en que la Ley $3 / 2007$, de rectificación registral de la mención relativa al sexo de las personas, otorga consecuencias jurídicas a dicho cambio. Ahora bien, se exige para ello que el solicitante acredite dos hechos (art. 4): diagnóstico por médico o psicólogo clínico de disforia de género y haber sido tratado médicamente durante al menos dos años "para acomodar sus características físicas a las correspondientes al sexo reclamado".

Si existía o no un derecho fundamental, con validez en todo el territorio nacional $^{12}$, al cambio de sexo no estuvo claro hasta la STC 99/2019, que lo consideró una facultad derivada del libre desarrollo de la personalidad (art. 10.1 CE) ${ }^{13}$. Este siempre fue más bien calificado como principio, y por tanto no parecía exigi ble directamente ante los tribunales ${ }^{14}$, pero si leemos entre líneas la sentencia,

8 En la base de datos de DIALNET, consultada en mayo de 2021, buscando "Defensor del Pueblo", así entre comillas, aparecen 797 documentos.

9 Un primer apunte de esta perspectiva en Escobar (2010: 251-255). Considero que solo desde este tipo de análisis podrá superarse el actual momento de marginalidad y legalismo que aquejan al Ombudsman en general: de interés, O'Brien (2018: 34 y ss.).

10 Sobre este y otros temas de la investigación pendiente sobre el Ombudsman, Hertogh y Kirkham (2018: 508-516), donde concluyen exigiendo "más teoría, más investigación empírica y más investigación comparativa".

11 Poco antes del cierre de estas páginas (26 de marzo de 2021), y en medio de la polémica sobre el tema entre los socios del Gobierno de coalición, los Grupos Parlamentarios Republicano y Plural presentaron una proposición de ley "para la igualdad real y efectiva de las personas trans", cuyo articulado comienza diciendo: "La presente Ley tiene por objeto promover y garantizar la igualdad real y efectiva de las personas trans, mediante el reconocimiento del derecho a la identidad de género libremente manifestada, como exigencia de la dignidad humana y requisito para el libre desarrollo de la personalidad". La izquierda abraza el liberalismo.

12 Desde 2009, diversas leyes de las Comunidades Autónomas vinieron a reconocer el derecho al cambio de sexo: Navarra (Ley 12/2009), País Vasco (Ley 14/2012), Galicia (Ley 2/2014), Andalucía (Ley 2/2014) o Cataluña (Ley 11/2014). Si se trata, como enseguida veremos, de un derecho fundamental, el apoyo competencial de esta normativa es más que discutible, a la vista del art. 149.1.1 $\mathrm{C} \mathrm{CE}$, aunque también es cierto que si el Estado no regula, las Comunidades Autónomas tienen una cierta legitimidad para hacerlo. Fue sabio al respecto el art. 72 de la Ley Fundamental de Bonn, según el cual "en el ámbito de la legislación concurrente, los Länder tienen la facultad de legislar cuando y en la medida en que la Federación no haya hecho uso mediante ley de su competencia legislativa".

13 Ya lo había dicho previamente la STS (Sala de lo Civil) de 15 de julio de 1988 (ROJ 5590/1988), pero sin ninguna argumentación. Para más detalles, Vidal (1989: 987 y ss.). Para un análisis exhaustivo del problema, Palau (2016). Esta doctrina, y alguna otra relevante que podría citarse (p. ej., Belda, 2004: 150-152, o Elvira, 2013: 7-10), en su afán por justificar constitucionalmente el derecho al cambio de sexo, cae a mi juicio en el error de apoyarlo en diversos preceptos, no solo en el art. 10.1 (que me parece la sedes materiae más correcta), sino también en los arts. 14, 15, 16 y 18, con el problema añadido, en los tres últimos casos, que exigen ley orgánica para su desarrollo.

14 La doctrina suele afirmar que no es un derecho fundamental, pero no argumenta por qué; por cierto, normalmente confunde libre desarrollo de la personalidad con derecho general de 
realmente el libre desarrollo de la personalidad es un derecho (pues existe un interés de las personas con garantía judicial ${ }^{15}$ ), aunque de momento solo un derecho de libertad. Es decir, no se puede impedir a una persona su decisión libre de cambiar de sexo, y de existir algún impedimento no justificado, cabría recurrir a los tribunales contra él. Los dos informes que la ley exige para el cambio registral pueden a mi juicio ser calificados de impedimentos indirectos, pero solo sobre un elemento de su posible contenido, el que exige una actuación pública. Una persona puede cambiar de sexo sin interferencia pública, pero si quiere que el cambio conste en el registro (lo que parece un derecho a un acto administrativo, derivado necesariamente del derecho de libertad $\left.{ }^{16}\right)$, tiene que cumplir ambos requisitos, que en principio podríamos considerar razonables ${ }^{17}$.

La Constitución se aplica directamente, y si existe un interés de una persona reconocido en la Constitución (según la STC 99/2019), entonces necesariamente deberá tener garantía judicial, y por tanto contamos con los dos elementos definitorios de un derecho fundamental, siendo indiferente que carezca de reserva de ley o de recurso de amparo ante el Tribunal Constitucional.

EI DP trata este problema, entre otras, en su respuesta a la queja 18000792, de 26 de junio de 2018, que consta como "aceptada". Un ciudadano reclamaba el cambio de su nombre en la tarjeta sanitaria expedida por el Servicio Madrileño de Salud ${ }^{18}$. La Consejería competente responde que lo hará, pero después de la rectificación de la inscripción registral prevista en la mencionada Ley 3/2007. Añade que, de momento y si el interesado lo pide expresamente, se le atenderá "por el nombre sentido" cada vez que reciba asistencia sanitaria, pero esto es mucho menos de lo que el ciudadano pedía.

EI DP no está de acuerdo con la respuesta de la Consejería, pero en ningún momento realiza una argumentación en derechos fundamentales, quedándose en un planteamiento bastante legalista. Cita a su favor:

libertad, que son cosas distintas. Si es porque la CE no dice "derecho al libre desarrollo de la personalidad", desde luego el razonamiento es pobre, pues no es preciso que literalmente se utilice este término. La ya citada STS de 15 de julio de 1988 había señalado: "el art. 10.1 de la Constitución Española establece como derechos fundamentales de la persona, entre otros, el del «libre desarrollo de la personalidad», término éste que en una proyección hermenéutica amplia autoriza a incluir los cambios físicos de forma del ser humano, siempre que ello no implique o suponga delito o cuando menos ilícito civil".

15 Los elementos del concepto de derecho subjetivo son tres: a) interés de una persona; b) reconocimiento en una norma jurídica; y c) garantía judicial. El interés es obvio. El elemento b) es el art. 10.1 CE (según la STC citada). En cuanto a la garantía judicial, es consecuencia (conceptual y necesaria) de lo anterior, y si la ley no lo prevé, o mejor, no lo permite, habría inconstitucionalidad por omisión. Precisamente el supuesto de partida de la STC 99/2019 es la alegación de la ausencia de reconocimiento legal del derecho a los menores de edad.

16 En algunos casos, los derechos de libertad admiten un contenido (mejor que garantía) de derecho de organización o procedimiento, en este caso con carácter accesorio y no esencial.

17 Se trata de no convertir el derecho en capricho. En el fondo, late también detrás un problema de gran calado, tan viejo como los vicios del consentimiento del Derecho civil, y que habría que trasladar a la concepción constitucional de la libertad: ¿hasta qué punto somos realmente libres?, o ¿se puede limitar la libertad en beneficio del propio individuo que la ejerce? En el momento de cierre de este trabajo (mayo de 2021) continúa abierto el debate en el interior del Gobierno de coalición sobre los requisitos exigidos para el cambio de sexo en una futura ley.

18 La tarjeta sanitaria individual es un documento administrativo que resulta válido en todo el sistema nacional de salud y que sirve para acreditar el acceso a las prestaciones del referido sistema. El RD 183/2004 establece que todas las tarjetas sanitarias estarán vinculadas a un código de identificación personal único para cada ciudadano en el sistema nacional de salud, que es uno de los datos que deben incluirse en su anverso. 
a) La Ley de Madrid 3/2016, de protección integral contra la LGTBifobia [sic], que obliga a la Administración madrileña a adoptar todas las medidas necesarias para que la documentación administrativa, en las áreas contempladas en dicha norma, sean adecuadas a la diversidad sexual y afectiva de las personas LGTBI así como garantizar, en el acceso a los servicios y prestaciones públicas, que las personas transexuales puedan ser nombradas y tratadas de acuerdo con el género con el que se identifican. Añado que la norma no reconoce un derecho como tal sino una obligación administrativa cuyo cumplimiento en principio resultaría exigible por los interesados, lo que al final podría ser lo mismo, pero creo que el matiz es relevante.

b) La Ley de Madrid 2/2016, de Identidad y Expresión de Género, cuyo artículo 7.3 b) señala: "Los trámites para la expedición de la documentación administrativa prevista en la presente Ley serán gratuitos, no requerirán de intermediación alguna, y en ningún caso implicarán la obligación de aportar o acreditar cualquier tipo de documentación médica". Existe entonces una diferencia importante entre los requisitos madrileños para la documentación administrativa y los requisitos nacionales para el cambio registral; es decir, se podría obtener un documento administrativo de la Comunidad Autónoma acreditativo del nuevo sexo sin haber logrado previamente el cambio del mismo en el registro civil nacional.

c) La Orden de Madrid 1296/2016, sobre tarjeta sanitaria, establece en su artículo 5 que para su obtención será necesario verificar la identidad del solicitante, que deberá acreditar mediante el DNI u otros documentos. A ello el artículo 7 de la Ley 2/2016 añade que cuando, por la naturaleza de la gestión administrativa, se haga necesario registrar los datos que obran en el DNI, se recogerán las iniciales del nombre legal, los apellidos completos y el nombre elegido por razones de identidad de género.

Al final, el argumento clave es la interpretación teleológica del precitado artículo 7.3 b) de la Ley 2/2016, cuyo objetivo es "adecuar de forma completa la atención del sistema público madrileño a la identidad de género de la persona perceptora de la misma", a lo que el DP añade la finalidad (aquí por fin una cierta sensibilidad en derechos, superando la frialdad del lenguaje burocrático) de evitar "situaciones de sufrimiento por exposición pública o discriminación". En general, señala el DP, esta Ley "obliga a la Comunidad de Madrid a adoptar todas las medidas administrativas que aseguren que, en todos los procedimientos en los que participe la Comunidad, se obrará teniendo en cuenta que las personas deben ser tratadas de acuerdo con su identidad de género".

Como argumentos complementarios, el DP añade dos: otras Comunidades Autónomas no exigen el cambio registral para modificar el nombre en la tarjeta sanitaria, y no hay afectación al interés público: "la modificación del nombre en la tarjeta sanitaria individual no supone interferencia alguna en la identificación ni en el reconocimiento de los datos personales del paciente, una vez establecida la previsión de que los usuarios del Sistema Sanitario de la Comunidad de Madrid acompañen a su tarjeta el documento identificativo de la personalidad de su titular cuando así sea requerido".

En conclusión, el DP recomienda a la Consejería "emitir la tarjeta sanitaria individual de las personas transexuales recogiendo el nombre elegido por razones de identidad de género, sin que se requiera a sus titulares la previa concesión de rectificación de la mención registral de sexo", y añade: "Asimismo, se solicita la remisión de información complementaria sobre la creación efectiva de estadísticas públicas acerca de los resultados de los diferentes tratamientos, terapias e intervenciones a los que se alude en el artículo 21.1 de la Ley [2/2016]".

El caso era más sencillo de lo que parece, pues bastaba haber hecho un 
recordatorio del deber legal de cumplir con el artículo 7.3 b) de la Ley 2/2016. Puestos sin embargo a argumentar en derechos, lo que nunca sobra (en tanto refuerza notablemente la argumentación), el razonamiento podría haber quedado así:

El derecho al cambio de sexo es un derecho fundamental derivado del art. 10.1 CE.

El derecho al cambio de sexo incluye la obligación de la Administración de poner el nuevo nombre en la tarjeta sanitaria ${ }^{19}$.

Exigir para el cambio de nombre en la tarjeta sanitaria el cambio previo en el Registro Civil es una restricción no prevista en la ley (es más: la ley dice lo contrario) y carente de justificación.

Luego, la exigencia administrativa referida vulnera el derecho fundamental

A mayor abundamiento, el caso podría haberse enfocado desde el derecho a la no discriminación, pero esto no resulta ya necesario. Veamos ahora lo que de especial aporta la garantía del DP, y aquí destacaría tres cuestiones: a) el caso, de haberse llevado a la jurisdicción contencioso-administrativa, hubiera implicado mucho tiempo ${ }^{20}$ y dinero; b) se parte de un caso individual (no consta queja colectiva) pero la recomendación es general (no se dice: "emitir la tarjeta sanitaria a X" sino "emitir la tarjeta sanitaria a las personas transexuales", algo que los jueces no podrían haber hecho); c) aunque no consta que se haya realizado, el DP podría haber iniciado sin dificultad (basta enviar una consulta) una investigación de oficio para conocer si este mismo problema se está produciendo en otras Comunidades Autónomas, y seguidamente, en su caso, dictar una recomendación idéntica dirigida a todas ellas. La segunda parte de la recomendación parece apuntar a la futura puesta en marcha de nuevas actuaciones de oficio y también generales.

\section{Violencia de género: defecto de protección del derecho a la integridad}

La violencia de género seguramente puede ser calificada en España como un problema sistémico ${ }^{21}$, que leído en clave de derechos fundamentales, equivale a una vulneración estructural del derecho a la vida e integridad (art. 15 CE) de

19 Nótese que esta es la tesis principal, y que se está creando (sin decirlo) un nuevo derecho a la documentación, no previsto como tal, aunque derivable de normas de mandato a la Administración.

20 Primero habría que haber "forzado" el acto administrativo, pues según parece la exigencia denunciada en el caso se hizo de manera verbal. El ciudadano tendría que haberlo solicitado primero por escrito y seguramente la Administración o no le habría contestado o habría tardado meses en hacerlo.

21 En las últimas Observaciones Finales sobre España del Comité para la Eliminación de la Discriminación contra la Mujer (CEDAW por sus siglas en inglés), de 29 de julio de 2015 (documento disponible en https://tbinternet.ohchr.org/layouts/15/treatybodyexternal/ Download.aspx?symbolno=CEDAW\%2fC\%2fESP\%2fCO\%2f7-8\&Lang=en), este se manifestaba "alarmado por la prevalencia en el Estado parte de la violencia contra la mujer, incluida la violencia sexual, y por el alto porcentaje de mujeres que han muerto como resultado de la violencia de género en las relaciones de pareja. El Comité está especialmente preocupado por las siguientes cuestiones: a) La Ley Orgánica núm. 1/2004 no abarca la gama completa de la violencia de género fuera de la violencia dentro de la pareja; b) El número de niños asesinados por sus padres en el ejercicio de sus derechos de visita (20 entre 2008 y 2014); c) El deterioro de los servicios de protección de las mujeres que son víctimas de la violencia doméstica en distintas comunidades autónomas, en particular la limitada disponibilidad de casas de acogida para mujeres y niños". 

del DP en la materia, muy amplias y variadas ${ }^{23}$, escogeré su tratamiento del problema de las víctimas inmigrantes en situación irregular, un típico ejemplo de "discriminación múltiple". En su respuesta a la queja 19003799, de 19 de diciembre de 2019, cuyo contenido se desconoce ${ }^{24}$, el DP se olvida por completo del caso concreto (en realidad el lector no se entera del contenido de la queja presentada) y razona desde el primer momento dando por hecho que se trata de un problema estructural de nuestro país, aunque sin apenas utilizar (segundo ejemplo) el lenguaje de los derechos, como iremos comprobando.

En esta recomendación (que figura como "aceptada" en sus cuatro puntos ${ }^{25}$ ), el DP se centra en el déficit de protección del colectivo señalado. No hubiera costado mucho (y habría ganado en calidad y por tanto en capacidad persuasiva) dejar claro desde el comienzo dos tesis, más que nada porque no están consolidadas: a) el derecho fundamental a la vida e integridad exige acciones positivas (en sentido amplio) en primer lugar del legislador, dirigidas básicamente a prevenir de manera suficiente sus vulneraciones más graves y reiteradas ${ }^{26} ; b$ ) tales acciones positivas deben diseñarse y aplicarse en principio con carácter universal (el derecho a la vida e integridad es igual para todos) pero prestando especial atención a las personas en situación de vulnerabilidad (acciones positivas en sentido estricto), es decir, a mayor riesgo de vulneración del derecho, mayor intensidad de la protección pública ${ }^{27}$.

22 No creo que las mujeres sean un "grupo vulnerable" como tal, sino solo en determinados contextos. De entrada, conviene recordar que nuestra legislación de "violencia de género" es más bien contra la "violencia doméstica" (la producida por la pareja o expareja), no sobre la violencia contra las mujeres en general. Compárense los arts. 1 de la LO 1/2004 (violencia sobre las mujeres "por parte de quienes sean o hayan sido sus cónyuges o de quienes estén o hayan estado ligados a ellas por relaciones similares de afectividad, aun sin convivencia") y 2.1 del Convenio de Estambul (BOE de 6 de junio de 2014: "todas las formas de violencia contra la mujer, incluida la violencia doméstica").

23 Véase la síntesis de Ovejero (2019: 575-591).

24 El DP exagera la preservación de la identidad de los ciudadanos presentadores de queja, hasta el punto de que muchas ocasiones no sabemos qué están solicitando, lo que convierte no pocas recomendaciones en ininteligibles.

25 Habría que matizar, "aceptada formalmente", pues año y medio después no se ha cumplido lo que el DP recomendaba, que como veremos, era una modificación sustancial de la LO 1/2004.

26 Como es sabido, la tesis se formula por vez primera en la STC 53/1985, que declaró inconstitucional la primera ley del aborto precisamente por protección insuficiente del derecho a la vida. Después apenas hay referencias jurisprudenciales tan claras, y en todo caso ninguna sobre violencia de género. Por su parte, el Tribunal Europeo de Derechos Humanos sí ha abordado en numerosas ocasiones la cuestión de las obligaciones estatales de protección en general y contra la violencia de género en particular, aunque raramente ha señalado que la legislación interna incurría en defecto de protección; últimamente, por todos, Carretero (2020).

27 La cuestión de las acciones positivas (antes llamadas discriminación positiva) viene de lejos, y se amplía cada vez más a un heterogéneo catálogo de "grupos vulnerables". Doctrinalmente esta temática está también pendiente de construcción o al menos de consolidación, y para esto deberíamos comenzar aclarando hasta dónde llega la igualdad como derecho fundamental. Nuestro Tribunal Constitucional sigue erre que erre afirmando que este derecho no incluye un derecho a la diferenciación (tratar mejor a quienes están peor), y de esta forma las acciones positivas quedarían fuera de lo constitucionalmente exigible, en manos por tanto de la discrecionalidad del legislador de turno. En mi opinión, se contradice: p. ej., en la reciente STC 51/2021 vuelve a reiterar la "tesis", pero en la práctica está obligando a la Administración empresaria a tratar mejor a un funcionario con discapacidad. No se cuestionaba aquí la ley, pero en otros casos se han considerado inconstitucionales (por "discriminación indirecta" y para seguir la corriente al Tribunal de Justicia de la Unión Europea, mucho más avanzado) leyes "aparentemente neutras" por no tratar mejor a las mujeres que a los hombres. Pues bien, a mi juicio, tras la doctrina del DP se encuentra, en este y en otros 
La recomendación comienza afirmando que "La recepción de varias quejas relacionadas con agresiones sexuales a mujeres migrantes en situación irregular, ha puesto de manifiesto las graves consecuencias que acarrea que no sean consideradas plenamente como víctimas de violencia de género por parte de la legislación española, tal y como exige la aplicación del Convenio de Estambul". El tema parece entonces general pero bien determinado; sorprendentemente, como después veremos, la conclusión irá por otro lado, también general pero indeterminado. Nótese de entrada que el DP constata una diferencia de regulación en el Derecho internacional y en el Derecho nacional, pero no obtiene después partido suficiente de este contraste. Para afirmar una realidad fáctica ("graves consecuencias", aunque habría sido más correcto "violación reiterada de derechos fundamentales"), el DP no solo se apoya en los datos que obtiene de las "varias quejas" recibidas, sino también en los aportados por otras organizaciones: "De acuerdo con distintos informes de las organizaciones no gubernamentales en España [lamentablemente, no se citan las fuentes], y con el último publicado por la Red de Mujeres Latinoamericanas y del Caribe en 2018, las mujeres extranjeras sufren más agudamente la violencia de género en España. De acuerdo con los datos de 2017, por ejemplo, los asesinatos de mujeres españolas supusieron el $5 \%$ por cada millón de mujeres españolas en el país, mientras que los asesinatos de mujeres extranjeras afectaron al 30\% por cada millón. En cuanto al número total de víctimas implicadas en denuncias, el informe recoge que de las 158.217 denuncias recogidas en 2017 , el $69,6 \%$ lo fueron de mujeres españolas y el $30,9 \%$ de extranjeras, de modo que las españolas implicadas como víctimas en denuncias suponen el $6 \%$ por cada mil mujeres españolas, mientras que son el $24,7 \%$ por cada mil mujeres extranjeras residentes".

De acuerdo: el DP se apoya en fuentes de autoridad y en estadísticas para constatar un hecho, afirmado también por cierto en buenas investigaciones empíricas $^{28}$. Este problema de violación estructural, al menos en relación con las mujeres inmigrantes, seguramente tendrá causas complejas y variadas, pero el DP se centra (y seguramente no podía hacer otra cosa) en analizar las actuaciones (o más bien omisiones) de los poderes públicos en este campo. Señala que nuestra legislación requiere que la víctima denuncie judicialmente y obtenga una orden de protección o sentencia favorable para acceder al sistema de protección. El Decreto-Ley 9/2018 modificó el artículo 23 de la Ley Orgánica 1/2004, permitiendo acreditar la violencia mediante un certificado de los servicios sociales o de acogida públicos. Según el DP, "estos cambios para la acreditación de la condición de víctima sin necesidad de denunciar ocasionan efectos indeseables para las mujeres extranjeras en situación irregular". El DP no explica por qué de ese cambio legislativo se derivan "efectos indeseables" ni cuáles son éstos, y reconozco que no entiendo el argumento, pero dejémoslo ahí.

Continúa el DP concretando las distorsiones entre Derecho internacional y nacional: "Por otro lado, la protección a víctimas de violencia de género fuera de la pareja, en España no está adaptada a la Observación 21 a) del CEDAW ${ }^{29}$ y,

muchos casos, una concepción propia de la igualdad, que incluye el derecho a la diferenciación.

28 El DP repite la extraña costumbre (en comparación con otros países) de nuestros altos tribunales de no citar doctrina, lo que solo puede entenderse como mal entendida equidistancia. La bibliografía sobre la violencia de género e inmigración es muy abundante; por limitarnos a los libros, véase por todos, Antón (2013); los datos que demuestran la especial incidencia de la violencia en este colectivo (2013: 61-74).

29 Se refiere a las últimas Observaciones Finales sobre España, ya citadas, que en este apartado 
por tanto, no han sido incluidas en el ámbito de protección de la Ley Orgánica 1/2004". Y demuestra así la vulneración estructural, pero ahora parece que más en general, no solo en el ámbito de la inmigración: "Según la Macroencuesta 2015 de la Delegación del Gobierno contra la Violencia de Genero, la violencia sexual fuera de la pareja ha afectado alguna vez a 1.447 .687 mujeres -el 7,2\% de las mujeres de 16 y más años, residentes en España-. De ellas a 120.641 en el último año. El 40\% por violación (que solo denunciaron el 2,1\%)".

Según el DP, “Las asociaciones de mujeres [no cita cuáles, y se lo debíamos] manifiestan que hay impunidad y miedo a denunciar este tipo de violencia también considerada [por el Derecho internacional] violencia de género, por los peligros de la aplicación de la Ley de extranjería en el caso de mujeres extranjeras, y por la revictimización judicial, social y de los medios de comunicación". Con buen criterio, el DP comienza analizando si la legislación vigente facilita o dificulta la denuncia (en sentido amplio), necesaria para que la maquinaria protectora del Estado se ponga en marcha, llegando a la conclusión siguiente: "Varios aspectos recogidos en la legislación vigente tienen consecuencias negativas para las mujeres víctimas que son inmigrantes, pues en lugar de facilitar su ayuda y asistencia se complica aún más su realidad, cuando se encuentran en situación irregular". ¿Pero por qué no dice que vulneran sus derechos? Veamos (reconstrucción mía, pues la recomendación no siempre la cita correctamente) más despacio esta legislación. En primer lugar, el artículo 31 bis de la Ley Orgánica 4/2000, llamada de Extranjería, permite a las mujeres extranjeras en situación irregular denunciantes de violencia de género solicitar una autorización provisional de residencia en España. Sin embargo, al final señala: "Si del procedimiento penal concluido no pudiera deducirse la situación de violencia de género, se incoará [obligación, no habilitación] el expediente administrativo sancionador por infracción del artículo 53.1.a) [encontrarse irregularmente en territorio español] o se continuará, en el supuesto de que se hubiera suspendido inicialmente". Parece así que, si no hay sentencia condenatoria (pudo ser por falta de pruebas), la denunciante podría quedar en peor situación que antes de la denuncia, por lo que se entiende su temor a presentarla ${ }^{30}$.

EI DP critica también lo limitado del concepto legal de violencia de género, circunscrito a la existencia de una relación sentimental, sin contemplar las agresiones sexuales fuera de la relación de pareja, "pues de este modo se excluye el acceso de estas víctimas al sistema de atención, protección y ayuda establecido, incidiendo en la especial vulnerabilidad de este colectivo". Este déficit de protección afecta en realidad a todas las mujeres, por lo que nuevamente se pierde el hilo inicial.

Seguidamente encontramos un primer atisbo de razonamiento en derechos, pues el DP, con cita de la STS 1263/2018 ${ }^{31}$, se refiere al "carácter imperativo de las resoluciones del Comité CEDAW, y la responsabilidad del Estado por no actuar con la diligencia debida para implementar sus obligaciones internacionales".

"instan" al Estado español a "Revisar su legislación sobre la violencia contra la mujer en vigor a fin de que incluya otras formas de violencia de género, por ejemplo, la violencia ejercida por cuidadores, la violencia policial y la violencia en espacios públicos, lugares de trabajo y escuelas".

30 Para más detalles, Mella (2013).

31 Se trata del mediático caso González Carreño, en el cual el Tribunal Supremo condenó a la Administración al pago de 600.000 euros, en concepto de responsabilidad patrimonial, por no haber dado cumplimiento a un Dictamen del CEDAW de 2014. Lo importante de esta Sentencia es que viene a reconocer el carácter vinculante de estos dictámenes en España; para más detalles sobre el caso, Gómez (2019). 
Pero de la vinculación (jurídica, se entiende) de las resoluciones (particulares) del Comité se pasa a afirmar, de forma poco clara (y el asunto lo merecía), la vinculación de sus recomendaciones generales, "entre ellas, y en relación con este caso, las que obligan a establecer un marco legal adecuado para responder a las situaciones de violencia de género. La Recomendación General 32 y la Observación 37 a) de la CEDAW para mejorar la protección, el acceso a los procedimientos y las condiciones de acogida de las mujeres y niñas solicitantes de asilo llama a evitar el uso de la violencia en los controles fronterizos; el establecimiento de planes de contingencia para las llegadas a las fronteras terrestres y marítimas y la aplicación de la perspectiva de género en todos los programas de asistencia". Salvo esta última recomendación, demasiado genérica y por tanto poco operativa, se comprueba que la CEDAW se está refiriendo a un nuevo problema (la violencia de género en frontera), sobre el cual el DP no aporta datos; es decir, no sabemos si realmente existe un problema de este tipo en España. El DP cambia en todo caso su argumentación inicial sobre el temor de las mujeres inmigrantes a denunciar (aunque sabemos que la denuncia no es necesaria), y concluye: "Es necesario mejorar los mecanismos para identificar a las mujeres y niñas más expuestas a situaciones de violencia de género en los movimientos migratorios, y contar con un sistema de protección internacional más ágil en la instrucción de los expedientes, con profesionales con formación en materia de género capaces de dar el tratamiento adecuado a mujeres y niñas con estas necesidades específicas", y de ahí pasa sin más a formular sus recomendaciones. Como se advierte en lo expuesto hasta ahora, el razonamiento es bastante caótico, pues se tratan problemas muy diferentes y con causas muy diversas, sin que encontremos una secuencia lógica entre unos temas y otros.

Las recomendaciones del DP finalmente son las siguientes:

a) "Que se haga uso de la iniciativa legislativa del Gobierno para que, de acuerdo con el artículo 2 del Convenio de Estambul, ratificado en el 2014 por España, se aplique el presente Convenio a todas las víctimas de violencia doméstica, prestando especial atención a las mujeres víctimas de violencia basada en el género". Es cierto que el DP no tiene por qué detallar la redacción concreta de las reformas legislativas que propone, pero en este caso la ambigüedad es tan alta que no se entiende bien su recomendación. Además, el Convenio es Derecho español, y resulta ya aplicable; de no ser así, habría que explicarlo mejor. En la medida en que el Convenio requiere actuaciones administrativas, y que estas (por razones de eficacia o de principio de legalidad) deben concretarse en una ley nacional, podría haberse hablado de inconvencionalidad por omisión.

b) "Que se realicen las modificaciones legislativas que sean necesarias [...] para implementar de forma efectiva las obligaciones recogidas en el artículo $1 \mathrm{c})$ del mencionado convenio internacional, de proteger a las mujeres contra todas las formas de violencia, y prevenir, perseguir y eliminar la violencia contra las mujeres y la violencia doméstica, mediante un marco global, de políticas y medidas legislativas de protección y asistencia para todas las víctimas de violencia contra las mujeres y la violencia doméstica". Parece entonces que el Convenio no puede aplicarse directamente y que exige ser concretado legislativamente mediante acciones administrativas específicas, pero esto va mucho más lejos del problema de las mujeres inmigrantes, que era el objeto inicial del procedimiento ante el DP.

c) "Que en uso de dicha iniciativa legislativa se modifique el artículo 1 de la [Ley Orgánica 1/2004], incluyendo en el objeto de la ley la definición de "violencia contra la mujer" acorde con el artículo 3 a) del Convenio de Estambul". Desde 
luego, esto es una alteración sustancial del sistema de protección previsto en la legislación vigente.

d) "Que, una vez modificado el objeto de la ley, se realicen todos los ajustes normativos necesarios para dar efectividad a la protección que el Estado ofrece frente a la violencia contra la mujer, en todas sus manifestaciones".

La recomendación, que comenzó afirmando las dificultades de las mujeres inmigrantes en situación irregular para protegerse frente a la violencia de género, no parece muy coherente en su argumentación, pues al final lo que recomienda (y esto es lo más relevante) poco tiene que ver con las premisas iniciales. En el "fallo" se olvida del problema específico de la inmigración, de las recomendaciones de la CEDAW al respecto y de los problemas derivados de la normativa vigente en España, en particular del temor de las inmigrantes a denunciar. Todo se confía a una modificación legislativa, ampliando a la violencia procedente de fuera de la pareja un modelo de protección que hasta ahora se ha revelado bastante ineficaz. Por los datos del propio DP, los problemas de las inmigrantes en situación irregular son otros, y de dos tipos: los que provocan el miedo a denunciar y los que implican una protección insuficiente, tanto social como frente a las agresiones en frontera.

Desde una reconstrucción del asunto en clave de derechos y centrado en el hilo discursivo original (quien mucho abarca poco aprieta), el razonamiento podría haber quedado así:

La violencia contra la mujer implica una vulneración de su derecho a la vida e integridad.

Este derecho es universal y debe ser protegido a todas las víctimas por igual.

Las víctimas inmigrantes en situación irregular están menos protegidas, ya que:

a) Tienen miedo a denunciar, entre otras cosas porque la norma A señala que, si lo hacen, pueden ser expulsadas.

b) Se producen frecuentes agresiones en las fronteras.

Por tanto, se recomienda:

a) Derogar la norma A.

b) Ampliar los medios de control en las fronteras, mediante las acciones B y $\mathrm{C}$.

\section{IV. ¿Existe un derecho a la ciudad?}

La queja 17022447, de 17 de junio de 2019 (que también consta como aceptada), se refiere inicialmente a unos solares propiedad del Ayuntamiento de Telde (Las Palmas). Según los propios servicios técnicos municipales, uno de ellos es "un solar con vallado en mal estado, que permite el acceso al mismo; estructura de planchas metálicas en estado de abandono, así como escombros, restos inorgánicos varios y vegetación espontánea". Estos mismos servicios recomendaban que se adoptasen con urgencia las medidas correctoras oportunas para evitar riesgos, y en concreto "que se proceda a la limpieza del solar para que quede desprovisto de cualquier tipo de residuo, así como de vegetación que pudiera albergar animales o plantas portadoras o transmisoras de enfermedad o producir malos olores". En el mismo expediente ante el DP se habla de otros solares de titularidad privada (parece así que la queja se amplía de oficio), inspeccionados por una empresa de control integral de plagas, la cual recomendó también medidas correctoras.

EI DP comienza recordando la normativa administrativa aplicable: "el deber de conservación viene contemplado en la normativa urbanística como uno de los deberes que integran el estatuto de la propiedad y obliga a los propietarios 
de toda clase de terrenos y construcciones a conservar y mantener estos en condiciones de seguridad, salubridad y ornato público" (RDLEG 7/2015, art. 15; Ley de Canarias 4/2017, art. 168). Si este deber es incumplido, afirma el DP, debe ser exigido (conceptualmente estamos en presencia de una garantía administrativa ${ }^{32}$ ) por la autoridad municipal: "la legislación urbanística atribuye a los ayuntamientos la competencia de vigilar el cumplimiento del deber legal de conservación y rehabilitación que los propietarios tienen respecto de los terrenos y construcciones cuya titularidad ostenten, competencia que se integra dentro de la labor municipal de inspección urbanística, y que generará, en caso de transgresión del mencionado deber, la actuación administrativa subsidiaria por medio de órdenes de ejecución, cuyo incumplimiento incluso habilita a la Administración pública a adoptar determinadas medidas". El artículo 25.2 de la Ley 7/1985, de Bases de Régimen Local, dispone que los entes locales tienen encomendadas, entre sus competencias, la protección de la salubridad pública y el medio ambiente urbano, así como la disciplina urbanística. Dicho precepto atribuye a los municipios una amplia capacidad genérica de actuación para promover actuaciones y prestar los servicios públicos necesarios para cumplir con sus obligaciones y encontrar una solución a las situaciones que se le plantean. Conforme al mismo, el Ayuntamiento de Telde es competente en materia de protección de la salud pública en el término municipal, por tanto puede actuar por sí mismo y adoptar medidas para la adecuada conservación de unas parcelas que genera problemas de salubridad. Interesa destacar que el DP salta, sin mucha explicación, directamente de la competencia a la obligación administrativa, como si ambas fueran la misma cosa ${ }^{33}$ : "si las parcelas denunciadas no se encuentran en condiciones de seguridad, salubridad y ornato público, es claro que ese Ayuntamiento debe requerir a sus propietarios para que procedan a realizar los trabajos necesarios que garanticen su salubridad" (cursivas mías). Tampoco encontramos una clara distinción entre las obligaciones relativas a la propiedad

32 Sobre la diferencia entre cumplimiento y garantía administrativa de los derechos, Escobar (2018: 155 y ss.). Sobre la inspección y sanción como garantía de los derechos fundamentales, Escobar (2012: 659-662).

33 La cuestión es crucial. Los derechos fundamentales se cumplen muchas veces mediante actuaciones administrativas, pero luego la legislación administrativa olvida la perspectiva de derechos y las obligaciones públicas quedan diluidas bajo la excusa de la discrecionalidad. Por eso resulta importante aclarar que las competencias administrativas no son habilitaciones sino obligaciones exigibles por los ciudadanos, al menos cuando pueda argumentarse mínimamente que estos se encuentran afectados por aquellas. Para eso se "inventó" en el siglo XIX el concepto de interés legítimo, ahora no tan distinto del derecho subjetivo, por mor de su inclusión conjunta en el art. 24.1 CE; para una buena reinterpretación de todo ello, Medina (2016: 153 y ss). El llamado derecho a la ciudad, como enseguida veremos, tiene como principal virtualidad destacar la exigibilidad de bienes comunes; en términos de dogmática de los derechos, convertir su carácter objetivo en derecho fundamental subjetivo. En el ejemplo: nadie se ve afectado directa y personalmente en su salud y sin embargo cualquiera puede exigir al municipio que adopte las medidas necesarias para evitar daños a la salud en el futuro. En su tratamiento del tema, García de Enterría y Fernández (2020b: 92-105), aunque destacan la importancia del art. $18.1 \mathrm{~g}$ ) LBRL (derecho de los vecinos a "exigir la prestación y, en su caso, el establecimiento del correspondiente servicio público, en el supuesto de constituir una competencia municipal propia de carácter obligatorio") se quedan a mi juicio cortos e incluso caen en contradicción. Resumo su planteamiento: las obligaciones administrativas conectadas a derechos fundamentales son exigibles desde la Constitución, pero si las leyes no concretan esta exigibilidad (y ellos se quejan de que no suelen hacerlo), lo único que puede hacerse es plantear cuestión de inconstitucionalidad ante el Tribunal Constitucional (dificilísima en la práctica, y más cuando estamos fuera del objeto del amparo); sin embargo, al final, afirman que "las eventuales imperfecciones de la Legislación aplicable podrán ser corregidas, al menos parcialmente", por los tribunales ordinarios. Un intento de solución en Escobar (2012: 567-572). 
pública y a la propiedad privada, y parece que esto resulta indiferente, lo que revela una interesante forma de control, aunque indirecta, de los particulares ${ }^{34}$ : "de constatarse esta situación [de afectación a la salubridad de los vecinos, el Ayuntamiento] debe velar para que sus propietarios cumplan con su obligación, ordenando [...] la ejecución de los trabajos y proceder a su ejecución subsidiaria en caso de incumplimiento. Todo ello de cara a impedir que su estado constituya un peligro para la salud y seguridad de las personas". En ningún momento el DP cita derecho fundamental alguno. Concluye recomendando, con cita de la legislación urbanística estatal y autonómica, "garantizar el cumplimiento de la obligación que tienen los propietarios de toda clase de terrenos y construcciones de mantenerlos en condiciones de seguridad, salubridad y ornato público", y sugiriendo "girar visita de inspección a las parcelas mencionadas en el informe emitido por la empresa de control integral de plagas [...] a fin de comprobar si cumplen las condiciones de seguridad, salubridad y ornato público exigibles. En caso negativo, dictar orden de ejecución de las actuaciones que sean precisas para garantizar que aquellas reúnan unas condiciones higiénicosanitarias adecuadas, con advertencia de las facultades municipales en caso de incumplimiento (imposición de multas coercitivas o ejecución subsidiaria)".

Las respuestas, también de 2019, a las quejas 18005503 (contra el Ayuntamiento de Cigales, Valladolid, por acumulación de basura y presencia de animales en solar privado), 19011905 (contra el Ayuntamiento de Foios, Valencia, por vivienda en riesgo de desplome) y 19011199 (contra el Ayuntamiento de Cogolludo, Guadalajara, por el mismo tema) son muy similares a la anterior y prácticamente idénticas en su argumentación. En todas estas actuaciones, sorprende de nuevo la falta de mención a derechos fundamentales, y habría sido interesante la configuración por el DP de un "nuevo derecho" a la ciudad 35 , tema levemente apuntado en alguno de sus informes anuales ${ }^{36}$. Aunque nos encontramos ante

34 Recordemos que el objeto de control del DP no incluye a los particulares; no obstante, podría hacerlo indirectamente (con un subterfugio similar al utilizado por el Tribunal Constitucional para revisar en amparo intervenciones privadas sobre los derechos): si una Administración pública debe supervisar a los particulares, y no lo hace o lo hace a medias, entonces es esa Administración quien vulnera el derecho. Al respecto, por todos, Ponce (2012).

35 El llamado derecho a la ciudad está en construcción y apenas contamos con una dogmática jurídica mínima que lo haya delineado. Habríamos de partir de tres documentos clave, que ni siquiera llegan a la categoría de soft law pero que fueron aprobados por entidades públicas municipales: la Carta Mundial por el derecho a la ciudad (2004), la Carta Europea de salvaguardia de los derechos humanos en la ciudad (2012) y la Carta-Agenda Mundial de derechos humanos en la ciudad (2012). Dejando fuera las facultades que encajarían en el contenido de figuras específicas de derechos expresamente reconocidos, parece que se limita, según el último de los documentos citados, a algo tan indeterminado como el "derecho a una ciudad constituida como comunidad política municipal que asegure condiciones adecuadas de vida a todos y todas y que procure la convivencia entre todos sus habitantes y entre estos y la autoridad municipal". Algo más concreto resulta el "derecho a disponer de espacios y recursos para la práctica de una ciudadanía activa y a que los espacios de convivencia y trabajo sean respetuosos con los valores de los demás y con el valor del Pluralismo", una especie de urbanismo en sentido amplio y subjetivizado; de interés, Ponce (2019: 84-94), destacando correctamente cómo las Defensorías del Pueblo podrían contribuir a la garantía de este nuevo derecho, p. ej. (como en la recomendación que estoy comentando) mediante la reducción y orientación de la discrecionalidad administrativa municipal.

36 En la p. 661 del Informe de 2019 se señala que el alquiler turístico implica "un deterioro del medioambiente urbano y en particular, del "derecho a la ciudad" como el derecho de toda persona a que las ciudades respondan a las necesidades humanas. Tal derecho deriva del artículo 45 de la Constitución, al dar a la expresión "medio ambiente adecuado para el desarrollo de la persona" un sentido integral, que incluye los elementos artificiales, creados por el ser humano y que hacen posible el desarrollo de las personas, así como su bienestar". Aunque de forma algo rudimentaria pero clara y precisa, el DP hace aquí (lamentablemente 
uno de los pocos supuestos de acción pública (art. 4 f) RDLEG 2/2008: "para hacer respetar las determinaciones de la ordenación territorial y urbanística"), resulta sin duda difícil que los ciudadanos la ejerzan, por el coste que implica: si nadie en concreto está afectado individualmente, no es probable que los ciudadanos pongan en marcha la maquinaria de la justicia. En este sentido, la actuación del DP cubre este déficit, y seguramente logrará el mismo resultado, de forma más rápida y económica, que la jurisdicción contencioso-administrativa.

A mi juicio, el razonamiento del DP quedaría más reforzado de haberse formulado así:

El derecho fundamental a la ciudad, aquí derivado del art. $45 \mathrm{CE}$, incluye el derecho de los ciudadanos a la conservación de los espacios, públicos y privados, en condiciones de seguridad, salubridad y ornato.

Los municipios tienen el deber correlativo de garantizar dichos derechos, al menos cuando existe riesgo para la seguridad y salud de la ciudadanía, haciendo uso de las potestades previstas en el ordenamiento, y en particular de la sanción y ejecución subsidiaria.

Luego los municipios, si no cumplen con dicho deber, vulneran el derecho a la ciudad.

\section{V. ¿Derecho fundamental a la reparación de las víctimas del terrorismo?}

El derecho fundamental a la vida e integridad incluye el derecho a la reparación de las víctimas ${ }^{37}$; como las violaciones al derecho suelen proceder de particulares, esto se traduce, de entrada, en la obligación del legislador de establecer dicha reparación. Aquí hay varias opciones: la vía penal (arts. 109-122 CP), la vía civil (art. 1902 CC) o la vía administrativa (arts. 32-37 LSP y leyes sectoriales). En realidad, el DP podría realizar recomendaciones de reforma legislativa en los tres ámbitos, pero centrémonos en el último: si el daño fue producido por el funcionamiento "normal o anormal" de la Administración, habría que acudir a las reglas (y a su amplia casuística) de la responsabilidad patrimonial. El caso de las víctimas del terrorismo es inequívocamente penal, pero será frecuente que las víctimas se queden sin cobrar, por no encontrarse al culpable (según las asociaciones de víctimas, aproximadamente un tercio de los asesinatos de ETA están sin resolver) o por insolvencia del condenado. La responsabilidad administrativa no parece fácil de demostrar en estos $\operatorname{casos}^{38}$. Sin embargo, el legislador puede otorgar reparaciones, sin que ello resulte a mi juicio obligatorio ${ }^{39}$. Así viene haciéndolo (por citar solo las leyes posteriores a la CE) desde

como excepción) una contribución importante a la construcción de (nuevos) derechos, saltándose el positivismo legalista habitual.

37 La doctrina sobre el art. 15 CE pasa de puntillas sobre esta cuestión. La STC 181/2000, respondiendo a varias cuestiones de inconstitucionalidad sobre la ley de responsabilidad civil por accidentes de circulación, afirma la existencia de este deber estatal de reparación, aunque la cosa está mucho más clara en la extensa y heterogénea doctrina del TEDH sobre el art. $2 \mathrm{CEDH}$.

38 Entre las excepciones, STS de 27 de diciembre de 1988, tras demostrarse la falta de diligencia del servicio de desactivación de explosivos, o STS de 27 de marzo de 1998, por quedar acreditada la omisión administrativa de contar con un sistema de detección de explosivos nada menos que en la Comisaría General de la Exposición Universal de 1992. En la doctrina, Soro (2006: 251 y ss.), si bien insistiendo en la línea tradicional de responsabilidad objetiva, criticada en Escobar (2021: 6-29). Más correctamente, aunque sin poder todavía abandonar el dogma de la responsabilidad objetiva, Garrido (2013: 121 y ss).

39 Resulta claro que estas reparaciones "especiales" quedan fuera de la responsabilidad patrimonial de la Administración; p. ej., SSTS de 18 de febrero de 1991 y de 1 de junio de 1999. 
el Real Decreto-Ley 3/1979 (desarrollado por RD 484/1982), seguido de la Ley Orgánica 9/1984 (art. 24), la Ley 33/1987 (art. 64, desarrollado por RD 673/1992), la Ley 32/1999 (desarrollada por RD 1912/1999) y de la vigente Ley 29/2011 (desarrollada por RD 671/2013) ${ }^{40}$.

EI DP no se pronuncia sobre si el derecho a la vida exige la reparación estatal en todos los casos de pérdida de aquélla por actos de particulares. Parece claro que no, ¿pero entonces nada tiene que ver este asunto con los derechos fundamentales? Recordemos una vez más que la función del DP no es otra que la garantía de los derechos fundamentales. En la respuesta a la queja 18010794, de 24 de julio de 2018, ni siquiera se razona en términos de derechos fundamentales, aunque (nuevamente) la recomendación bien podría reformularse en esa dirección. Veamos: aunque la Constitución no lo exige, el legislador ha decidido que en determinados casos la Administración repare a las víctimas del terrorismo, y así sucede en la Ley 29/2011, pero con unos requisitos tan estrictos que dejan fuera a quienes, dada la época en que sucedieron los hechos, no pudieron denunciar o acreditar el daño psicológico ${ }^{41}$.

La queja que motivó la actuación del DP fue presentada por un coronel retirado de la Guardia Civil que prestó sus servicios en la provincia de Vizcaya entre 1976 y 1985, y que vio denegada su solicitud de indemnización, por no cumplir los requisitos legales. El coronel adujo que en aquella época el entorno de miedo era tal que las víctimas raramente denunciaban las situaciones de acoso y amenazas que sufrían; además, antes de 1986, los Cuerpos de Seguridad no solían instruir diligencias policiales (y por tanto el asunto no llegaba a los tribunales) y en cambio aconsejaban a las víctimas que abandonaran su localidad de residencia. A su vez, la asistencia en salud mental no se integró en el servicio sanitario general hasta 1986, por lo que antes de esa fecha las víctimas de amenazas terroristas no pudieron aportar los informes psiquiátricos y psicológicos después exigidos por la ley.

El coronel estaba bien asesorado y se lo puso fácil al DP, proponiendo que los medios probatorios exigidos para la acreditación de las amenazas se ajustaran y acomodaran a los existentes en la época y momento en que la víctima sufrió la amenaza, mediante la adición a los tres supuestos del artículo 3 bis de la Ley (sentencia firme, diligencias judiciales o incoación de proceso penal) de un cuarto supuesto que recoja el derecho a "utilizar los medios de prueba pertinentes para su defensa" del 24.2 CE y la regla general del artículo 77 LPC, según el cual los hechos relevantes para la decisión de un procedimiento podrán acreditarse por cualquier medio de prueba admisible en Derecho (el recurrente había aportado un recorte del diario EGUIN, de 23 de febrero de 1978, donde se publicaron amenazas contra él y su familia). Citó el coronel en el mismo sentido un Informe de la Abogacía General del Estado de 17 de octubre de 2014, que aunque tampoco razonaba en derechos fundamentales, afirmaba que el cambio legislativo estaría "razonablemente justificado". Pues bien, sin

Sobre los supuestos de responsabilidad subsidiaria del Estado, véase el art. 121 CP. Desde luego, podría construirse una regla de responsabilidad subsidiaria del Estado para todos los casos de insolvencia del autor (civil o penal) del daño, pero aquí sí podríamos dar una cierta entrada al análisis económico del Derecho: nos acercaríamos a la bancarrota del Estado, y en todo caso (y esto es más relevante), no parece justo cargar a este (léase a la colectividad) por la culpa de otros.

40 Para más detalles sobre esta evolución normativa, Pérez Rivas (2016: 157 y ss).

41 El artículo 5 de la Ley 29/2011 requiere acreditar que las amenazas terroristas fueran directas y reiteradas y que existiera sentencia firme, procedimiento penal incoado o diligencias judiciales sobre tales hechos. Para tener derecho a indemnización deberían además acreditar la existencia de daño psicológico mediante el correspondiente informe médico. 
más argumentación, el DP concluye recomendando "valorar la procedencia de la reforma de la Ley 29/2011 [...], en la que recogiendo el criterio manifestado por la Abogacía del Estado, se incluya un nuevo inciso en el artículo 3 b) de la misma, que permita acreditar, mediante cualquier medio de prueba admitido en derecho, la condición de amenazado o coaccionado por actividad terrorista, aun cuando no exista sentencia firme, ni se hayan practicado diligencias judiciales ni incoado proceso penal". El único argumento es por tanto el de la autoridad de la Abogacía del Estado, y esto no puede ser. Lo razonable puede ser un criterio, y la LODP lo viene a permitir como argumento, pero desde luego es poco contundente. ¿No habría sido posible argumentar en derechos fundamentales? Creo que sí, y con un doble razonamiento:

1) El art. $24 \mathrm{CE}$ incluye el derecho a presentar cualquier medio de prueba.

Algunas garantías del art. $24 \mathrm{CE}$ son aplicables al procedimiento administrativo, y entre ellas el derecho a presentar cualquier medio de prueba, tal y como reconoce el art. $77 \mathrm{LPC}^{42}$.

Luego, limitar los medios de prueba en un determinado procedimiento administrativo vulnera el art. $24 \mathrm{CE}$.

El problema en todo caso no es de prueba sino de los requisitos legales para obtener la prestación. Aunque la prueba se admitiera, de poco serviría pues acreditaría un hecho considerado no resarcible por la ley. La argumentación debe discurrir entonces por los cauces del principio de igualdad (art. $14 \mathrm{CE}$ ):

2) Si la ley reconoce un derecho a la reparación, debe fijar su círculo de beneficiarios de forma no discriminatoria.

Resulta discriminatorio para muchas de las víctimas anteriores a 1986 exigir unos requisitos casi imposibles de cumplir.

Luego, exigir denuncia a las víctimas anteriores a 1986 vulnera su derecho fundamental a la igualdad.

Con este doble razonamiento, fundado en la vulneración de dos derechos fundamentales, la ley es inconstitucional por omisión parcial. No sería por tanto conveniente sino también necesario modificarla. EI DP no puede hacerlo ya (por el transcurso del plazo) aunque podría hacerlo un juez planteando cuestión de inconstitucionalidad. En todo caso, no es lo mismo decir que el cambio legislativo propuesto es conveniente que decir que es necesario. Nótese por último que nuevamente de un caso particular (el del coronel retirado) se da el salto a la constatación de una vulneración estructural de derechos, y por tanto la recomendación es general (reforma legislativa), no particular.

\section{Nuevas dimensiones de la religión e intimidad: banderas a media asta y divulgación de la homosexualidad}

En relación con derechos "clásicos" defensivos, la actuación del DP puede resultar útil al abrir nuevas perspectivas, proponiendo soluciones menos formalistas que las habitualmente ofrecidas por los tribunales contencioso-administrativos, de haber llegado a ellos el caso. Veamos dos ejemplos, donde el razonamiento en principio podría adoptar una mejor perspectiva de derechos fundamentales, por encontrarse estos más claramente afectados:

42 El Tribunal Constitucional considera aplicable el derecho a la prueba en el procedimiento administrativo sancionador (p. ej., SSTC 2/1987 o 9/2018). En todo caso, aunque no fuera derecho fundamental, parece claro que es derecho subjetivo de rango legal. 
1) La respuesta a la queja 17007488 (que consta también como "aceptada"), de 11 de mayo de 2018, es interesante, pues aquí el DP subjetiva un principio constitucional explícito43 ("Ninguna confesión tendrá carácter estatal"), traducido como neutralidad religiosa del Estado, que puede ser exigido por los ciudadanos, luego (si nos atenemos a la función del órgano prescrita en el art. $54 \mathrm{CE}$ ) parece que nos encontramos ante un derecho fundamental44, aunque esto no se diga claramente. El asunto parte de la queja presentada por un grupo de militares contra la colocación a media asta de la bandera española, en establecimientos militares, durante la Semana Santa45. En esta ocasión el razonamiento es muy completo: tras citar el artículo 16.3 CE y alguna de la jurisprudencia que lo interpreta (quizás la selección no es muy acertada)46, así como la normativa aplicable47, el DP se plantea la cuestión de hecho señalada por el Tribunal Constitucional como clave para la solución de este tipo de conflictos: la bandera a media asta, ¿tiene una significación incompatible con el deber de neutralidad religiosa? Al respecto, el DP señala lo siguiente: "nadie puede sentir que, por motivos religiosos, el Estado le es más o menos próximo que a sus conciudadanos. Además, las Fuerzas Armadas están llamadas a identificarse con la sociedad española de la que forman parte y a la que sirven, y están constitucionalmente obligadas a

43 Se trata de un paso decisivo para la superación del positivismo o, mejor dicho, del formalismo jurídico: los principios son Derecho, y por tanto exigibles. Si además estos principios no se encuentran explicitados en el Derecho vigente, el avance es todavía mayor. Si no queremos acercarnos peligrosamente al iusnaturalismo, debemos extraer estos principios del mismo Derecho, como es el caso, y no de la Moral, aunque reconozco que la demarcación es sutil. Correctamente, García de Enterría y Fernández (2020a: 107-114).

44 Los derechos fundamentales existen si existe una norma constitucional que los reconoce con fórmulas tales como "se garantiza", "se reconoce", "todos tienen derecho a" u otras equivalentes, pero también cuando la jurisprudencia (o en su caso el DP) permite a una persona exigir algo a su favor, con apoyo en una norma de otro tipo, como un mandato a los poderes públicos e incluso un principio; en este último caso estaríamos hablando de subjetivación de un principio.

45 Tampoco esta vez encontramos un acto administrativo formalizado, y su única demostración es una nota de prensa de 26 de abril de 2018, donde se indicaba: "como ya es tradicional en estas fechas, la bandera nacional ondeará a media asta desde las 14.00 horas del 29 de abril (Jueves Santo) hasta las 00.01 horas del 1 de abril (Domingo de Resurrección) en todas las unidades, bases, acuartelamientos militares, así como en la sede central del Ministerio de Defensa y las delegaciones territoriales del Departamento, tal y como se ha ordenado en las últimas décadas, con las excepciones puntuales de 2010 y 2011 en la sede del Ministerio de Defensa".

46 EI DP cita las SSTC 5/1981 (Estatuto de Centros Escolares, FJ 9), 46/2001 (Secta Moon, FJ 4) y, sobre todo, 34/2011 (Patrona del Colegio de Abogados de Sevilla, FJ 4), donde el Tribunal Constitucional señaló que no basta con constatar el origen religioso de un signo identitario para que deba atribuírsele un significado actual que afecte a la neutralidad religiosa. La cuestión se centra en dilucidar, en cada caso, si ante el posible carácter polisémico de un signo de identidad, domina en él su significación religiosa en un grado tal que permita inferir razonablemente una adhesión del ente o institución a los postulados religiosos que el signo representa. Si atendemos al fallo de esta última sentencia, y de otras que podrían citarse, y en especial a la 177/1996, sobre una parada militar en honor a la Virgen (donde no se declaró inconstitucional este tipo de actos castrenses), tengo mis dudas de que el Tribunal Constitucional diera la razón a los militares recurrentes ante el DP, más teniendo en cuenta que no se les obligó a hacer nada.

47 La Ley 39/1981, sobre el uso de la bandera de España, establece que el "tratamiento y honores que deben ser prestados a la bandera de España se regirán por lo que reglamentariamente se disponga y en el caso de las Fuerzas Armadas, por sus disposiciones específicas" (art. 2.3). Debe acudirse entonces al Reglamento de Honores Militares (RD 684/2010), cuyo art. 3.2 preceptúa que no se rendirán honores salvo los fúnebres, y la bandera permanecerá izada a media asta ininterrumpidamente día y noche cuando el Gobierno decrete luto nacional. Y, en el artículo 36, se relacionan las personalidades con derecho a honores fúnebres militares. Sobre esta normativa, el DP concluye: "no se establece, en ninguno de los supuestos regulados, el izado de la bandera a media asta en Semana Santa". 
la neutralidad religiosa, en función de los intereses públicos que representan. Resulta por tanto más adecuado a la lógica de un Estado aconfesional prescindir de unos honores militares de tanto significado como es el izado de la bandera de España a media asta, en una festividad religiosa tan principal como es la Semana Santa". Parece entonces que se da el presupuesto de hecho identificado por el Tribunal Constitucional como violatorio del deber de neutralidad: la bandera a media asta en Semana Santa tiene un significado inequívocamente religioso48. Por ello, el DP recomienda "que, en lo sucesivo, las órdenes del izado a media asta de la bandera de España se ciñan exclusivamente a los supuestos previstos en el Real Decreto 684/2010"49. No se entiende por qué no dijo "que, en lo sucesivo, las órdenes de izado a media asta de la bandera de España respeten el artículo $16.3 \mathrm{C}^{\prime \prime}$.

Como se advierte, la recomendación, que partió de una queja concreta en un establecimiento concreto, termina de nuevo teniendo un alcance general, pues se dirige a todos los establecimientos militares, y no a uno en particular: nuevamente, una medida estructural que difícilmente habría podido ser impuesta por los tribunales.

El razonamiento del DP es correcto, pero habría quedado más claro y completo así:

Existe un derecho fundamental a la neutralidad religiosa del Estado50.

Este derecho se ve afectado cuando el Estado emite un mensaje que implica adhesión a los postulados de una determinada religión.

El izado a media asta de la bandera de España en Semana Santa en establecimientos militares implica adhesión a los postulados de la religión católica.

La ley no prevé dicho izado.

Luego, el izado equivale a una violación del derecho fundamental a la neutralidad religiosa del Estado.

2) La recomendación de 25 de junio de 2020 responde a la queja 19008159, y se dirige a la Secretaría de Estado de Justicia, constando como "aceptada y no realizada". La cuestión clave en el caso es, para el DP, dilucidar "la posible afectación [rectius, vulneración] al derecho a la intimidad que causa la preceptiva publicación de edictos matrimoniales en los expedientes de autorización de matrimonio cuando los contrayentes son personas homosexuales". Por fin, el planteamiento comienza con la perspectiva de derechos fundamentales. Recuerda el DP que "los edictos son instrumentos de garantía que anuncian un casamiento para que todos los que tuviesen noticia de algún impedimento que pueda incidir en la celebración de dicho matrimonio puedan denunciarlo, de modo que el instructor pueda actuar en consecuencia. En las indicaciones

48 Aquí está el punto más discutible del caso: valorar este hecho como manifestación de la religión católica. Siguiendo este razonamiento, también la misma festividad de Jueves y Viernes Santo podría resultar inconstitucional.

49 Un tema colateral, que el DP no se plantea, es el alcance del principio de vinculación positiva de la Administración a la ley (en sentido amplio, pues aquí se trata de un reglamento): ¿puede la Administración, en este caso la Administración militar, hacer cosas que la ley no prevé?

50 Otro posible enfoque del problema es partir de la libertad religiosa, pero resulta demasiado forzado considerar que esta se ve afectada (el problema es la relevancia de la injerencia) por actos que ni impiden ni castigan ni dificultan ejercer las propias convicciones religiosas, ni siquiera en la faceta negativa de esta libertad. Otra opción, más correcta, habría sido entender que los entes públicos como tales no tienen libertad religiosa (o, mejor aún, libertad de expresión de ideas), y que por tanto los actos públicos a favor de una determinada religión son nulos, aunque no afecten a ningún derecho fundamental concreto de personas determinadas. En esta línea, aunque sobre libertad ideológica, puede verse la reciente STC 5/2021 (no vulnera la libertad de expresión prohibir a los presidentes de federaciones territoriales de fútbol -considerados entes públicos- manifestarse a favor de determinadas candidaturas). 
aparecen expresamente la identidad de los contrayentes; su nombre, apellidos y DNI, fecha y lugar de nacimiento, nombre de los padres, nacionalidad y estado civil. El hecho de que no se mencione expresamente el sexo de los contrayentes no es óbice para que con los datos que se exigen se identifique fácilmente su orientación sexual".

Veamos primero la normativa aplicable. Según el artículo 56 CC (redacción según Ley 15/2015), “Quienes deseen contraer matrimonio acreditarán previamente, en acta o expediente tramitado conforme a la legislación del Registro Civil, que reúnen los requisitos de capacidad y la inexistencia de impedimentos o su dispensa". Por su parte, el artículo 243 del Reglamento del Registro Civil de 1958 (redactado por RD 1917/1986) señala: "Se publicarán edictos o proclamas por espacio de quince días exclusivamente en las poblaciones en cuya demarcación hubiesen residido o estado domiciliados los interesados en los dos últimos años y que tengan menos de 25.000 habitantes [...]. Los edictos anunciarán el casamiento con todas las indicaciones contenidas en el artículo 240 y con el requerimiento a los que tuviesen noticia de algún impedimento para que lo denuncien".

EI DP considera esta normativa desfasada, pensada para "una sociedad pretecnológica, en la que no había suficientes medios técnicos para desarrollar una gestión segura y rápida en los pequeños municipios de los datos personales registrados y custodiados por los Registros públicos". Recuerda que la Ley 20/2011 realizó una importante modernización del Registro Civil (recientemente mejorada en la Ley 6/2021), fortaleciendo su carácter electrónico y las herramientas tecnológicas para la gestión más segura de los asientos registrales, prestando además especial protección a la intimidad de la persona. Con esta reforma "se facilita a los instructores de los expedientes el acceso a la información necesaria para, por ejemplo, celebrar un matrimonio en un pequeño municipio, respetando las normas de elaboración de expedientes matrimoniales y siendo respetuosos con la intimidad de los contrayentes, en especial en aquellos casos en los que se pueda generar dificultades, cuando la publicación de los edictos matrimoniales pueda implicar la revelación no deseada de la orientación sexual de los contrayentes". El DP concluye recomendando a la Secretaría de Estado: “1) Que adopte las medidas administrativas que sean necesarias para facilitar la elaboración de expedientes matrimoniales más respetuosos con la intimidad de los contrayentes; 2) Que se haga uso de la iniciativa legislativa del Gobierno para reformar y actualizar el Reglamento del Registro Civil en relación con la exigencia de publicación de edictos matrimoniales en pequeñas poblaciones, y que se permita que, siempre que sea posible y de forma prioritaria, el instructor del expediente matrimonial verifique los requisitos de capacidad y la inexistencia de impedimentos o su dispensa de los contrayentes, a través de la consulta a los recursos técnicos puestos a disposición por los propios sistemas registrales". Como se advierte, la recomendación 1 es ambigua, y seguramente innecesaria si se cumpliera la recomendación 2. Esta última es técnicamente incorrecta (debió decirse, "iniciativa reglamentaria"), y resulta poco contundente, pues el DP no se define sobre el problema de fondo que él mismo planteó al comienzo (la publicación en edictos, ¿afecta o vulnera el derecho a la intimidad?). Parece así que la reforma sería meramente aconsejable, pero a mi juicio debió haberse dicho que resultaba necesaria. En realidad, nuevamente falta toda argumentación sobre el derecho fundamental implicado, en este caso la intimidad. La celebración de un futuro matrimonio, ¿es un dato íntimo? No creo que esto pueda afirmarse con carácter general, a la luz de los usos sociales a los que remite el artículo 2.1 de la Ley Orgánica 1/1982: la inmensa mayoría de las personas no ocultan si están casadas o no. Definir qué sea la intimidad no 
debería quedar al arbitrio de cada persona sino definirse con criterios objetivos ${ }^{51}$, aunque estos puedan evolucionar. Tampoco el Tribunal Constitucional es muy claro al respecto: define frente a qué protege la intimidad (el "conocimiento de los demás" o "la curiosidad ajena") pero no qué datos son los protegidos por la intimidad; al final, lo más relevante son "las pautas de nuestra cultura", y a partir de ahí, la jurisprudencia va seleccionando, en una especie de lista abierta, qué datos pueden considerarse íntimos (y cuáles no), porque (entiendo) una amplia mayoría de personas no querría que se divulgaran, y por tanto protegidos por el derecho fundamental. La orientación sexual puede objetivamente considerarse un dato íntimo ${ }^{52}$ : habrá personas (y cada vez más), por ejemplo, a quienes no importe que se sepa que son homosexuales ("salir del armario"), pero habrá otras que prefieren mantener esto en secreto, y hay que respetarlo.

De esta forma, la publicación en edictos, aunque tras las modificaciones tecnológicas del Registro pueda ser innecesaria, no vulnera en sí misma la intimidad, solo si los futuros contrayentes son homosexuales. No parece que quepa una recomendación interpretativa del artículo 243 del Reglamento del Registro Civil, pues el precepto se formula en términos imperativos y no prevé excepciones. Tal y como está redactado, vulnera el derecho a la intimidad de las personas homosexuales, aunque estas bien podrían renunciar a él ${ }^{53}$. Por tanto, lo procedente habría sido proponer una reforma reglamentaria, pero no como mera sugerencia sino como obligación constitucional. Por un lado, puede ser aceptable dejar al Ministerio una cierta discrecionalidad, pero en casos tan claros como este, no estaría de más ayudarle a redactar de manera correcta la norma.

Reconstruyendo el razonamiento del DP en términos de derechos fundamentales, la recomendación podría haber quedado así:

La divulgación, aunque indirecta, de la condición homosexual de una persona, afecta a su derecho a la intimidad.

El art. 243 del Reglamento del Registro Civil, en tanto impone la publicación sin excepciones, por edictos y en poblaciones de menos de 25.000 habitantes, de la futura celebración de un matrimonio afecta al derecho a la intimidad de las personas homosexuales.

Dicha afectación no está prevista en norma con rango de ley y carece hoy día de justificación, dada la informatización del Registro Civil; en todo caso, no sería proporcionada, pues existen otros medios para asegurar el objetivo de la norma, que es garantizar el cumplimiento de los requisitos para contraer matrimonio.

Luego, el art. 243 del Reglamento del Registro Civil es inconstitucional por

51 Estos dos criterios de determinación del concepto de intimidad son denominados por DíezPicazo (2013: 281-282), respectivamente formal y material. Apuesta, con nuevos argumentos, por el segundo, y observa que es el "predominantemente" seguido por el Tribunal Constitucional.

52 Así viene a afirmarse, con poco atinada argumentación, en la ya citada STC 99/2019, FJ 4 b). La jurisprudencia del TEDH es ya prolija, pero se refiere a la vida privada (como derecho de libertad) y no a la intimidad propiamente dicha; para un recuento, Arzoz (2015: 377-387). Son más concretas sobre la afectación a la intimidad de la revelación de la orientación sexual del perjudicado las SSTS (Civil) 600/2012, 666/2014, 280/2015, 605/2015 o 684/2020, en todas ellas dando por hecho esta afectación, sin mayor esfuerzo argumentativo. Por su parte, la STS 480/2019 considera que hay afectación, pero no vulneración del derecho a la intimidad.

$53 \mathrm{El}$ tema de la renuncia de derechos fundamentales sigue sin estar claro. Por lo general, la jurisprudencia viene a admitirla, aunque muchas veces con matices, si se trata de una renuncia (o decisión de no ejercer el derecho) en casos concretos, nunca con carácter general. P. ej., sobre la renuncia al derecho de huelga, SSTC 11/1981, 38/1990, 145/1992, 189/1993, 332/1994 o 51/2003. En la doctrina, apenas contamos con un apunte de debate en Frumer y Villaverde (2013). Por mi parte, soy partidario de admitir la renuncia con carácter general, pues por definición los derechos se ejercen cuando su titular quiere ejercerlos. 
omisión relativa (no prevé excepciones para las personas homosexuales que no deseen dar a conocer su orientación sexual), debiendo adicionarse al precepto la siguiente frase: "Los futuros contrayentes que deseen preservar el secreto de su orientación sexual podrán solicitar la exención de la publicación por edictos del anuncio del casamiento".

\section{Bibliografía}

Antón García, L. (2013). Violencia de género y mujeres inmigrantes (tesis doctoral). Barcelona: Universidad Pompeu Fabra.

Arlettaz, F. y Gracia Ibáñez, J. (2020). La investigación en derechos humanos desde la sociología jurídica. En C. De La Cruz-Ayuso, y otros, La investigación en derechos humanos. Posición y método. Cizur Menor: Aranzadi.

Arzoz Santisteban, X. (2015). Artículo 8. Derecho al respeto de la vida privada y familiar. En I. Lasagabaster Herrarte (dir.), Convenio Europeo de Derechos Humanos. Comentario sistemático. Cizur Menor: Civitas. $3^{a}$ ed.

Belda Pérez-Pedrero, E. (2004). Transexualidad y derechos fundamentales: protección integral sin la utilización del factor sexo como diferencia. Cuadernos de Derecho público, 21, 127-161. Disponible en: https://revistasonline.inap. es/index.php/CDP/article/view/707

Carretero Sanjuán, M. (2020). El Tribunal Europeo de Derechos Humanos ante la violencia contra la mujer. Anales de Derecho de la Universidad de Murcia, 1, 1-26. Disponible en: https://doi.org/10.6018/analesderecho.452691

Díez-Picazo, L. (2013). Sistema de derechos fundamentales. Cizur Menor: Civitas. $4^{\mathrm{a}}$ ed.

Elvira, A. (2013). Transexualidad y derechos. Revista General de Derecho Constitucional, 17.

Escobar Roca, G. (2008). Defensorías del Pueblo en Iberoamérica. Cizur Menor: Aranzadi.

Escobar Roca, G. (2010). Interpretación y garantía de los derechos fundamentales por el Defensor del Pueblo: análisis empírico, reconstrucción teórica y propuesta de futuro. Teoría y Realidad Constitucional, 26, 229-258. Disponible en: https://doi.org/10.5944/trc.26.2010.6921

Escobar Roca, G. (2012). Derechos sociales y tutela antidiscriminatoria. Cizur Menor: Aranzadi.

Escobar Roca, G. (2017). Manual de derechos e intervenciones y sistematización de recomendaciones. Alcalá de Henares: PRADPI. Disponible en http:// pradpi.es/documentos trabajo/DT24 Escobar Codigo.pdf

Escobar Roca, G. (2018). Nuevos derechos y garantías de los derechos. Madrid: Marcial Pons.

Escobar Roca, G. (2019). Investigación en derechos humanos. En Argumentación e investigación en derechos humanos. Valencia: Tirant lo Blanch.

Escobar Roca, G. (2021). Preparando la RC tras la pandemia (A propósito del incumplimiento del derecho a la vida e integridad de los profesionales sanitarios, STS 1.271/2020). Revista de Responsabilidad civil, circulación y seguro, 57-1, 6-29.

Fariñas Dulce, M. J. (1994). Sociología del Derecho versus análisis sociológico del Derecho, Doxa 15-16, 1013-1023. Disponible en: https://doi.org/10.14198/ DOXA1994.15-16.51

Frumer, P. y Villaverde Menéndez, I. (2013). La renunciabilidad de los derechos fundamentales y de las libertades públicas. Madrid: Fundación Coloquio Jurídico Europeo. 
García de Enterría, E. y Fernández, T. R. (2020a). Curso de Derecho administrativo I. Cizur Menor: Civitas. 19a ed.

García de Enterría, E. y Fernández, T. R. (2020b) Curso de Derecho Administrativo II. Cizur Menor: Civitas, $16^{\mathrm{a}}$ ed.

Garrido Mayol, V. (2013). La reparación a las víctimas del terrorismo: de la responsabilidad a la solidaridad. En A. Català i Bas y F. García Mengual (coords.), El reconocimiento de las víctimas del terrorismo a través de la legislación y la jurisprudencia (pp. 119-139). Universidad de Valencia.

Gómez Fernández, I. (2019). Qué nos enseña el caso de Ángela González Carreño sobre el recurso al derecho internacional de los derechos humanos en los procedimientos ordinarios. Revista Aranzadi Doctrinal, 7, 1-7.

Hertogh, M. y Kirkham, R. (2018). An agenda for future research: towards a general ombuds-science. En Research Handbook on the Ombudsman. Cheltenham: Edward Elgar.

Kucsko-Stadlmayer, G. (2008), European Ombudsman-Institutions. Viena: Springer.

Medina Alcoz, L. (2016). Libertad y autoridad en el Derecho administrativo. Madrid: Marcial Pons.

Mella Méndez, L. (2013). El tratamiento de la víctima de violencia de género en la normativa española de extranjería. Revista Internacional y Comparada de Relaciones Laborales y Derecho del Empleo, 1-1, 1-35.

O'Brien, N. (2018). Ombudsmen and public authorities: a modest proposal. En M. Hertogh, y R. Kirkham, Research Handbook on the Ombudsman. Cheltenham: Edward Elgar.

Ovejero Lucas, A. M. (2019). España. En FEDERACIÓN IBEROAMERICANA DE OMBUDSMAN, XVII Informe sobre derechos humanos: violencia de género. Madrid: Trama.

Palau Altarriba, X. (2016). Identidad sexual y libre desarrollo de la personalidad (tesis doctoral). Universidad de Lleida.

Pérez Rivas, N. (2016). Las ayudas compensatorias a las víctimas de terrorismo: análisis de la Ley 29/2011 y su reglamento de desarrollo. Estudios de Deusto, 64 (2), 157-188. Disponible eh http://dx.doi.org/10.18543/ed-64(2)-2016pp157-188

Ponce Solé, J. (2012). El ejercicio privado de funciones públicas en el moderno derecho público: la supervisión por los Ombudsmen de los privados a propósito del nuevo papel del Defensor catalán. Alcalá de Henares: PRADPI.

Ponce Solé, J. (2019). El Ombudsman y el derecho a la ciudad. En G. Escobar Roca (coord.), Las Defensorías del Pueblo iberoamericanas ante la Agenda 2030. Alcalá de Henares: PRADPI.

Soro Mateo, B. (2006). Terrorismo y responsabilidad patrimonial de las Administraciones Públicas. Anales de Derecho de la Universidad de Murcia, 24, 251-266. Disponible en: https://revistas.um.es/analesderecho/article/ view/57891

Vidal Martínez, J. (1989). ¿Se incluye el cambio de sexo (transexualidad) en el libre desarrollo de la personalidad al que se refiere el artículo 10.1 de la Constitución española? Revista General de Derecho, 534, 987-1029. 